\title{
Epistemic Awareness of Doxastic Distinctions: Delineating Types of Beliefs in Belief-Formation
}

\author{
By Tennyson Samraj"
}

Doxastic distinctions help us define the basis and biases in belief-formation. Empirical and extra-empirical justification play an important role in determining doxastic distinctions. When we distinguish the different types of beliefs, we understand (1) that there are basically three kinds of beliefs, namely, verifiable, falsifiable, and unfalsifiable beliefs. Empirical justification provides the basis for establishing the veracity of verifiable and falsifiable beliefs. Extra-empirical justification provides the basis for establishing the veracity of unfalsifiable or irrefutable beliefs. (2) Verifiable or falsifiable beliefs that are reductive require the mandatory acceptance of their truth. However, unfalsifiable beliefs which are non-reductive require the volitional acceptance of their truth. Because there is both empirical and extra-empirical justification in belief-formation, we can accept beliefs with or without, against, or regardless of empirical evidence. Unfalsifiable beliefs do not mean that these beliefs are unjustifiable; it simply means that these beliefs are not empirically justifiable. Understanding the basis and biases of belief-formation is to be aware of how we come to know what we believe. As empirical basis allows us to hold beliefs based on either the principle of confirmation or falsification. Extra-empirical basis, namely phenomenological conjectures, allows us to hold beliefs founded on existential assertions. The intent of this paper is to present doxastic distinctions to help us understand the basis and biases associated with belief-formation. As long as epistemic claims are accepted, and their content is considered believable, the means used to arrive at those beliefs must also be respected. Every doxastic distinction not only provides the basis for belief-formation but also defines the role and limits of both empirical and extra-empirical justification in belief-formation. When we recognize the different types and different ways of justifying beliefs: we understand (1) why we can accept beliefs with or without evidence; against or regardless of empirical justification, and (2) know when to define beliefs as Plato argued as justified true belief and when to define beliefs as justified beliefdecisions.

Keywords: beliefs, justified true belief; justified belief-decisions, empirical and extra-empirical

\section{Introduction}

Doxastic distinctions provide us an understanding of the basis and biases in belief-formation. While reality can be understood as either being mind-dependent or mind-independent, beliefs about reality are defined as either being physical or metaphysical. Justification of beliefs can be either empirical or extra-empirical. Empirical justification provides the basis for verifiable or falsifiable beliefs that are

"Professor, Burman University, Lacombe, Canada. 
reductive in nature. The acceptance of reductive beliefs is non-volitional. Extraempirical justification provides the basis for unfalsifiable or irrefutable beliefs that are non-reductive in nature. Belief in the cognitive self (sentience), rational self (sapience), volitional self (freedom), moral self (morals), and the divine self (God) are considered non-reductive in nature (Kierkegaard 1987). Acceptance of nonreductive beliefs is volitional. 'Unfalsifiable' beliefs do not mean they are unjustifiable beliefs; it simply means that they cannot be empirically falsified ${ }^{1}$. This, however, does not give us the liberty to believe in what is impossible (Wilkinson 2016). What it means is that beliefs can be justified for reasons other than what is empirically justifiable. Beliefs based on extra-empirical justification are believable as phenomenological conjectures. Phenomenological conjectures provide the basis for the veracity of metaphysical beliefs. From Plato's time, epistemology has tried to define the different types of beliefs without defining the role empirical or non-empirical justification play in defining the types of beliefs in belief-formation. In this paper, an attempt is made to show how belief-distinctions explain belief-formation, keeping in mind the end-goal of belief is "believing" in both physical and metaphysical truths (Engel 2004). While beliefs can be rational or empirical, verifiable or unverifiable, falsifiable or unfalsifiable, all beliefs are mental states. As mental or cognitive states, they can be defined, defended, and believed with or without, against, and regardless of empirical evidence because the empirical proof is evidence only for reductive beliefs and not the basis for nonreductive beliefs.

Plato argued both in Theaetetus and Meno that knowledge can be defined as justified true belief. This was challenged by Gettier, who argued that the tripartite analysis-namely, the truth condition, the epistemic condition, and the justification condition can only prevent lucky guessing but cannot prevent lucky truth (Gettier 1993). Hume and Kant's distinguished knowledge being either a priori or $a$ posterior based on how we come to know what we know. Hume argued that beliefs are either sense-evident or self-evident, as such beliefs are either synthetic or analytic. Kant argued beliefs are either contingent or necessary- 'true' in a given world or 'true' in all possible worlds. Pojman argued that beliefs are either caused or chosen, as such beliefs are either volitional or non-volitional. Popper and Russel argued that beliefs depending on how beliefs are ascertained are either confirmable or falsifiable. In medieval times due to the question of the ambiguity of sentences, beliefs were considered either as de dicto or de re. Tarski's argued that when beliefs are defined as true or false, beliefs are considered either 'closed' or 'open' (Tarski 1993). Kierkegaard (1987, p. 16) argued that while empirical beliefs can be considered as being either true or false, extra-empirical beliefs or phenomenological conjectures are an either/or matter. Foundationlists and coherentists argue that beliefs are basic or non-basic, depending on whether other beliefs support beliefs or not.

When we recognize the nature of different types of beliefs: we (1) understand why we can accept beliefs with or without; against or regardless of empirical evidence, (2) understand when the acceptance of beliefs are mandatory or nonvolitional and when the acceptance of beliefs are non-mandatory or volitional. (3)

\footnotetext{
${ }^{1}$ In scientific terms falsifiability can be considered synonymous with testability.
} 
understand when to define beliefs as justified true belief and when to define beliefs as justified belief-decision. ${ }^{2}$ What we believe is either believable or unbelievable, falsifiable or unfalsifiable, verifiable or unverifiable, and what exists is either reducible or irreducible (Maudlin 2020). What is reducible is an empirical given and constitutes empirical knowledge; what is irreducible cannot be an empirical given, as such constitutes metaphysical knowledge. Metaphysical conjectures require a decision for or against what is known, hence called "justified beliefdecision." Both empirical and extra-empirical justification are used to establish the veracity of beliefs to avoid erroneous beliefs, for there are falsifiable and unfalsifiable beliefs. Empirical justification can take care of establishing the veracity of falsifiable beliefs, and extra-empirical justification can take care of the veracity of unfalsifiable beliefs, such as existential assertions as "I am free" and phenomenological conjectures such as "there is God" (Northcott 2019). What must be noted is that empirical evidence is one way but not the only way belief claims are justified.

\section{State Consciousness, Access Consciousness and Belief Distinctions}

State consciousness as defined by Rosenthal (2002, p. 208) and Access consciousness as defined by Block (2002, p. 407) allows us to know both what we know and how we know what we know in belief-formation. Access consciousness allows us not only to be aware of whether what we know is true or false but also allows us to classify doxastic distinctions (Conee 1988, p. 394). Belief distinction can be classified into three categories. (1) Epistemological distinction or a priori/ a posteriori distinction allows us to distinguish how we come to know what we know. What we know is either sense-evident or self-evident. (2) Semantic distinction or synthetic/analytical distinction allows us to hold beliefs either by virtue of experience or held as true by definition. Here, the distinction is based on whether the predicate is contained in the subject or not. (3) Metaphysical distinction or contingent/necessary distinction allows us to define beliefs as true in a given world or true in all possible worlds. Contingency and necessity or two metaphysical concepts that are indivisible. For instance, Newton's discovery of the contingency of gravity to a given mass and his projection of gravity as a fundamental part of the universe is a metaphysical claim. We can make metaphysical claims about what is true in all possible worlds based on what is true in a given world, even though we have not been to all possible worlds.

\section{A Priori /A Posterior Distinction-Epistemic Distinction}

Based on how beliefs are formulated, beliefs are either based on the data of one's senses or the dictates of one's reason. Beliefs are either sense-evident or selfevident. Beliefs are based on either experience or independent of experience. What

${ }^{2}$ I developed this idea in my book (Samraj 2007). 
is interesting about beliefs based on experience is that we do not have a choice in accepting or rejecting such beliefs. Belief in empirical truths is mandatory and non-volitional. We have to accept beliefs that are formulated by one's senses. Beliefs that are based on empirical or rational evidence, like in physical sciences or in mathematics, we have to believe. Sugar is sweet, or that $2+2=4$ are examples of beliefs that we have to accept. Thus there are two types of knowledge-namely empirical knowledge and rational knowledge, based on two types of justification - a priori justification and a posterior justification. Both a posteriori necessity and $a$ priori necessity provide the basis for the content of belief-formation.

\section{Synthetic/Analytical Distinction—Semantic Distinction}

Based on whether the predicate is contained in the subject or not, we can further distinguish beliefs based on whether beliefs are held as true by definition or held as true by or because of experience. Kant argued that the synthetic/analytical distinction was strictly based on whether the predicate is part of the subject or not (Kant 1991). Some beliefs are held as true by definition, and some beliefs are held as true by and because of experience. Beliefs that are true by definition entails that the predicate is contained in the subject. Beliefs that are held as true because of experience entail that the predicate is not contained in the subject. Triangle has three sides is an example where the predicate is contained in the subject - the triangle. Whereas sugar is sweet is such that the predicate is not contained in the subject. The predicate is either contained in the subject or the predicate is made known by experience. God is a good example of something that is true by definition. According to Epicurus, immortality is the only thing that we can be sure about God. Immortality defines who God is (Sher 2001, p. 616). The essence of God is based on the ideality of God-namely immortality and not the identity of God. We can comprehend the ideality of God without having any information about the identity of God.

\section{Contingent/Necessity Distinction-Metaphysical Distinction}

Based on whether a belief is true in a given world or true in all possible worlds, we can say that some beliefs are true in a given world, and some beliefs are true in all possible worlds, like $2+2=4$. The truths of such beliefs cannot be created, cannot cease to be, and cannot have a beginning. Such truths are true in all possible worlds. That is why it is necessary to assume both the necessity of the mind and the necessity for an eternal mind. Without having a mind, we cannot understand such eternal realities. So, there is by extension, and conjecture the need for an infinite and eternal mind in which these eternal truths reside. Does having a finite mind imply the possibility of an infinite or an immortal mind, as Socrates argued for in Phaedo? If we can understand eternal truths like mathematics but have a mind that has a beginning then, there must be an eternal mind in whose mind such realities consist and exist. We cannot understand the concept of contingency 
independent of understanding the concept of necessity. What is physical or empirical is true in a given world. But what is rational and metaphysical is true in all possible worlds.

\section{What Counts as Justification in Belief-Formation}

While empirical justification provides the basis for what is reducible, extraempirical justification provides the basis for what is irreducible. What counts or discounts as evidence? To argue that only empirical evidence counts as evidence is to discount the diverse ways of how beliefs are formulated. Empirical justification is crucial in holding inductive and reducible beliefs; as such, verifiability, falsifiability, demonstrability, repeatability, and predictability are considered essential to scientific investigation (Conee 1988, p. 389). However, irreducible beliefs related to metaphysical beliefs require an extra-empirical basis for an understanding of what is comprehended. As such, the relevance of questions, conjectures, and paradigms are considered essential in holding 'irreducible' beliefs. While empirical evidence can be the basis for reducible reality, we cannot provide empirical evidence for non-reducible realities, such as the self, freedom, and God. God is definable and believable when we become aware of de dicto and de re essence of God, even though the de re essence of God is inexplicable and the de re existence of God is unidentifiable (Swinburne 2004). We understand the de dicto necessity for God and the de re necessity of God when we define God as the creator and that God is a necessary being. However, both the de dicto essence and the de re essence of God cannot be verified or falsified by empirical evidence. Hence, the reality of God can be justified only by extra-empirical justification based on metaphysical or factual necessity (Swinburne n.d.). Similarly, the self and freedom can be held only as phenomenological conjectures. We are conscious of the self and the nature of intentionality, which is the basis for freedom, because of which, we can choose what to think, believe, and act (Brentano 2002).

When we have empirical evidence, belief is mandatory; however, when we have extra-empirical evidence, belief is not mandatory but volitional. While empirical verification is the basis for sense-evident beliefs and comprehension is the basis for self-evident beliefs, volition is the basis for the acceptance or rejection of phenomenological conjectures. What is phenomenological or existential is an either/or matter (Kierkegaard 1987). While the end process of empirical justification is the birth of verifiable, predictable, or practical knowledge, the end process of extra-empirical justification is the birth of existential and metaphysical conjectures. The phenomenological method allows us to use the physical, rational, and metaphysical eye to define what exists. The mind, as such is aware of what exists both in terms of what is reducible and what is irreducible. And at some point, what exits becomes irreducible either at the existential level like the self and freedom or at the quantum level —call it fields, energy, strings, or waves (Chalmers 2016, Greene 2019).

So, how do we acquire and justify beliefs in belief-formation? For the purpose of this study, there are four ways we can justify beliefs. We can justify beliefs by 
(1) the principle of confirmation (2) the principle of falsification, (3) the predictability principle, and (4) by phenomenological conjectures. Empirical justification can confirm or falsify epistemic claims. We can also confirm or falsify epistemic claims by the predictability principle. We can predict that the sun will rise tomorrow by past observation, or we can make a prediction based on possible future observation like Newton did-when he argued that the gravitational force on the moon would be $1 / 3$ to that of the earth. We can make a prediction based on past observation, but we can also make predictions based on future observation, which can confirm or disconfirm one's belief (Popper 2016). The first three justification can be done by empirical justification. However, the last justification, namely phenomenological conjectures, can be done without empirical justification. The basis for belief rests with the analysis of the conscious phenomena itself, such as intuitive conjunctures in mathematics and morals.

There are two types of evidence, empirical evidence, and extra-empirical evidence. Since there are extra-empirical justification for beliefs, we can hold beliefs with or without, against or regardless of empirical evidence. Evidence or justification for beliefs is not limited to only empirical evidence. To be able to verify, falsify, or predict reductive claims can be based on empirical justification. However, to accept unfalsifiable or irrefutable and non-reductive beliefs such as existential assertions, mathematical (Fibonacci) sequence ${ }^{3}$, ratios, infinity, and numbers can be possible only by phenomenological or rational justification. Why unfalsifiable or irrefutable beliefs require phenomenological or rational justification is because empirical justification cannot be the basis for its veracity-no empirical evidence to confirm, disconfirm or refute non-reductive claims. Existential assertions and metaphysical truths cannot be subjected to empirical testing methods because they are phenomenological conjectures based on the dictates of conscience or reason. Moral conjectures such as it is "better to be just than unjust"; "it is better to good than evil," or it is better not to do certain things than to do certain things cannot be falsified because they are lived truths. Morals are true because we discern right from wrong and choose to do right or wrong. Similarly, historical facts are not repeatable (Walls 2014); we cannot refute or go back to see things as they were. Creativity is a non-reductive reality, as such, cannot be reduced to a brain state. Creativity along with non-reductive beliefs, such as self, freedom, and the concept of God, can be accepted only as phenomenological conjectures.

Empirical evidence is one way but not the only way we can know about reality. There are two kinds of reality-reality that is dependent on the mind and reality that is not dependent on the mind. Physical reality is a reality that is mindindependent; mathematics and morals are two kinds of reality that are minddependent. However, while we cannot have mathematical truths without the mind, mathematics is not of our own making (Goodman and Snyder 1993). And if mathematical truth seems to be timeless, then there must be an eternal mind in whose mind such realities exist. The reality of mathematics and morals has no particular place or location, as such, referred to as logical or abstract space

${ }^{3}$ Mathematics-Fibonacci sequence and the Golden Ratio. Available at: https://www.youtube. $\mathrm{com} / \mathrm{watch}$ ? $=\mathrm{mVO} 2 \mathrm{dcuR} 7 \mathrm{P} 0$. 
(Herrick 1994). The mathematical reality, like moral reality, is non-spatial, nonphysical, and non-temporal. However, unlike math, morals entail action to do what is right -which is mind-dependent. The conscious self must 'will' to act. So there is reality and what we know of reality. But while what is real is mind-independent, what we know of what 'is' is mind-dependent.

\section{Types of Beliefs}

Beliefs as mental states can be defined, defended, and believed. Beliefs are referred to as proportional attitudes - (believing, hoping, or willing) because of the content of the propositions (Chisholm 2002, Engel 2004). However, the content of consciousness or propositions is such that it can be reductive or non-reductive. What we are cognitive of can be reducible or irreducible. If it is reducible, then it can be verified objectively, but if it is irreducible, then it would remain subjective and known only subjectively. So the mind is aware of beliefs that are reducible and beliefs that are irreducible. Both empirical evidence (reductive) and extraempirical evidence (non-reductive) evidence play an important role in belief formation. When we realize that at one level of our inquiry, what is known is irreducible, and at that level, there is no empirical evidence for a non-reductive given. So the types of beliefs define what role empirical or extra-empirical evidence provides for beliefs. All beliefs are subjective, but because of the nature of reality, beliefs that are reductive are objective, beliefs that are non-reductive remain subjective. We shall now see how and what role empirical or extraempirical justification play in distinguishing different types of beliefs.

Depending on whether beliefs are supported by other beliefs or not, beliefs are either basic or non-basic. Basic beliefs are beliefs that are not supported by other beliefs, and non-basic beliefs are beliefs supported by other beliefs. Foundationlists argue that there are basic beliefs and that these beliefs support other beliefs, but themselves are held unsupported. Coherentists argue that there are no basic beliefs and that all beliefs are supported by other beliefs (Conee 1988, p. 395). The basis for basic- beliefs is that it is immediate, non-inferential, and direct (Alston 1993, p. 42). The basis for non-basic beliefs is mediatory, inferential, and indirect (Alston 1993, p. 44). Either inductive/reductive justification or deductive/non-reductive justification can establish basic beliefs. Both empirical and non-empirical justification can provide the basis for basic beliefs, which would justify non-basic beliefs. However, while basic beliefs are considered indubitable, incorrigible, and infallible, non-basic beliefs are considered as coherent conjectures (Alston 1993, p. 45).

Depending on whether beliefs are caused or willed, beliefs are either volitional or non-volitional. Non-volitional beliefs are mandatory. We do not choose to believe in such beliefs - we have to believe in such beliefs. "Seeing is believing" (Pojman 1985, p. 40). On the other hand, volitional beliefs, such as belief in God ((Pojman 1985, p. 41), freedom, and the self, are such that we must choose to believe in such beliefs. For no empirical evidence can be proof or guarantee for such beliefs. For instance, seeing God is not proof of establishing the essence of God. Belief in the essence of God can be held as 'true' independent of proof for 
the existence of God (Pojman 1985, p. 39). Seeing the existence of God is not proof for the truth of the essence of God. That is why God does not and cannot create theists or atheists. We must choose to believe or disbelieve the essence of God. Volitional beliefs are beliefs that we must choose to believe independent of any evidence presented. Adam, who saw God, would have had to choose to believe or disbelieve that who he saw was God. Non-volitional beliefs are called causal beliefs because they can be traced to empirical or inductive justification. Volitional beliefs are considered existential beliefs because they can be traced to extra-empirical or deductive conjectures. We cannot verify or falsify non-volitional beliefs (Hume 2004); we can only deny or affirm volitional beliefs.

Depending on whether beliefs are self-evident or sense-evident, beliefs are considered being either a priori or a posteriori. Beliefs are either empirical or rational. How beliefs are obtained divides beliefs into two types. Experience is the basis for empirical truths. Rationality is the basis for rational truths. Empiricists argue for inductive reasoning in that inductive justification provides the basis the verifiability and the basis for prediction (Carnap 1946, Williams 2001). Rationalists argue for deductive conjectures in by accepting premises, postulates, and paradigms that provide the basis for rational truth. Empiricists argue that what is not sensed is nonsense, while the rationalists argue for the three laws of thought—namely the law of identity, the law of contradiction, and the law of excluded middle, as the basis for truth. Strict positivists argue that only sense verifiable beliefs should be considered as justifiable. However, rationalists argue that non-empirical justification or conjectures can and do provide justification for rational truths.

Depending on whether the predicate is contained in the subject or not, beliefs are considered as being either synthetic or analytical. Beliefs are either true because of experience or beliefs are true by definition, independent of experience (Williams 2001). That is why rejecting a priori truth involves a contradiction while rejecting a posterior truth does not. To say that sugar is not sweet is possible because one could be sick when one's transducers might not be functioning well. But to say a triangle does not have three angles is involves a contradiction for a triangle without three angles in no triangle at all. Synthetic knowledge -i.e., sugar is sweet is true only because of experience (Hume 2004, p. 81). On the other hand, triangles have three sides is true by definition alone. Here extra-empirical justification is the basis for analytical conjectures, while synthetic beliefs require some sought of empirical justification.

Depending on whether beliefs are true in a given world or true in all possible worlds, beliefs are considered as being either contingent or necessary. Contingent truths are true in a given world, and necessary truths are true in all possible worlds. Until the 1970s, it was held that only a priori necessity could be held as true is true in all possible worlds. After Kripke, we now know that we can also hold $a$ posteriori necessity as true in all possible worlds; once we know that water is $\mathrm{H} 20$, only what is H20 can be water is true in all possible worlds (Kripke 1980). However, a posterior necessity is established only because of empirical justification. However, metaphysical necessity can be established independent of empirical justification. Today most scientists would accept that scientific fact as probable or contingent in a given world. Here we can see the need for empirical justification to establish 
contingent truths and non-empirical analysis and conjectures to establish necessary truths.

Depending on whether beliefs are verifiable, beliefs are accepted or rejected as scientific or not scientific. Beliefs that can be observed and shared are accepted as scientific beliefs. Observation and experimentation produce positive sense data 4 . What does verifiability mean? If we say there is a black sheep, the positivists will only say that the visible part of the sheep is black ${ }^{5}$. Only sense experience shared with others is scientific knowledge 6 . Ideas related to God, freedom, or immortality of the soul is not observable hence not explicable and definitely not verifiable. The positivists will confirm what they can confirm - nothing more or nothing less. The positivists argue that observational justification is the basis for the correspondence theory of truth, as such would reject all forms of non-empirical justification as the basis for truth (Hempel 1935, p. 50). Here we notice that verifiable beliefs require empirical justification and non-verifiable beliefs require extra-empirical justification because non-verifiable beliefs deal with non-reductive truths.

Depending on whether beliefs are falsifiable, beliefs are considered as science or non-science-pseudoscience. If the emphasis is on the confirmation principle, then it is pseudoscience (Grattan-Guinness 2004); if the emphasis is on the falsification principle, then it is science (Popper 2016) - refutable in practice and in principle (Ayer 1946, p. 32). If a belief is not falsifiable, then it is not a matter related to science. Falsifiability means that it is inherently testable (Ajayi 2017). Falsifiable beliefs are beliefs that can be refuted or disproved. Falsifiable and verifiable are two different things ${ }^{7}$. "There is a unicorn" is verifiable but not falsifiable. All unicorns are white is falsifiable but not verifiable. ${ }^{8}$ Falsifiable means testability and implies refutability/predictability. We can predict a theory to be false in the future (Wigmore 2017). While we can verify or falsify empirical truth (Gezelter n.d.), Popper argued that it is impossible to know that a theory is true based on observation. Only 'falsification 'is deductively valid (Gezelter n.d.). If T, then O; Not O; Not-T. On the other hand, If T, then O; O; T, is deductively invalid. Falsifiability ${ }^{9}$ can disconfirm that all swans are white, but no amount of verifiability can establish the veracity that all swans are white. While we can either verify or falsify a claim, Popper argued that verification could not affirm as much as what falsification can assert. As such, Popper argued that falsification should be the line of demarcation between science and pseudoscience. Science has to be verifiable in practice and in principle.

Consider the statement-All crows are black. Are we talking about all crows that exist now, and does it include all crows in the past and future? For it is not possible to verify past crows. Verifying that crows are black cannot confirm that

\footnotetext{
${ }^{4}$ What is positivism. Available at: https://www.youtube.com/watch?v=9yCpTe9e-MI.

${ }^{5}$ What is positivism. Available at: https://www.youtube.com/watch? $\mathrm{v}=9 \mathrm{yCpTe} 9 \mathrm{e}-\mathrm{MI}$.

${ }^{6} \mathrm{What}$ is positivism. Available at: https://www.youtube.com/watch? $\mathrm{v}=9 \mathrm{yCpTe} 9 \mathrm{e}-\mathrm{MI}$.

${ }^{7}$ What are the value of unfalsifiable beliefs. Available at: https://philosophy.stackexchange. com/questions/51397/what-is-the-value-of-unfalsifiable-beliefs.

${ }^{8}$ What are the value of unfalsifiable beliefs. Available at: https://philosophy.stackexchange.co $\mathrm{m} /$ questions/51397/what-is-the-value-of-unfalsifiable-beliefs.

${ }^{9}$ Theory or hypothesis to be contradicted by evidence.--"All swans are white" is falsifiable because we can observe that black swans exist.
} 
all crows are black. One instance of disconfirmation that crows are not black does not negate that crows are not black, only that all crows are not black. Smoking causes cancer does not mean it will cause cancer. We can establish by instance confirmation that smoking causes cancer, but no amount of confirmation can establish that smoking will cause cancer. We cannot prove a hypothesis (that all crows are black) by confirmation but we can disprove it by disconfirmation or falsification - showing one instance of a non-black crow) (Olszewski and Alvaro Sandroni 2011, p. 788). Falsifiability could be an ideal basis for scientific theories, but verifiability is a sufficient basis for scientific investigation. Testability or predictability/repeatability rather than falsifiability is a minimal requirement for science (McNaughton 1999).

Depending on when and why beliefs are considered as unfalsifiable, beliefs are either phenomenological conjectures or existential assertions. Are there unfalsifiable beliefs - such as conjectures for non-spatial entities, non-temporal beings, and the self? "I am conscious," "there is God' "I am free" are unfalsifiable beliefs that are justifiable only by the phenomenological investigation. "Free will is not a testable hypothesis." The reality of freedom is neither verifiable nor falsifiable (McNaughton 1999); belief in liberty is unfalsifiable. Unfalsifiable beliefs are like axioms that cannot be proven wrong. Empirical justification cannot establish nor negate existential assertions and phenomenological conjectures. These do not come under sciences, according to Popper, because it cannot be verified or falsified by empirical means, as such, requires phenomenological investigation. That is why it is argued that we do not have freedom from metaphysics, but we do have the liberty to engage in metaphysics. Unfalsifiable beliefs are metaphysical conjectures. Metaphysical conjectures can be held as true with or without, against, or regardless of empirical evidence.

Depending on whether beliefs include the truth condition - truth or falsity/ right or wrong, beliefs are considered as being either 'open' or 'closed'. Open beliefs are beliefs that are not accompanied with the assertions of truth or falsity as part of the claims, such as "Snow is white". Closed beliefs or sentences that are accompanied with truth assertions as part of the claim, such as "It is true that snow is white." Adding the word truth or falsity to a statement does not make the statement true or false. While empirical justification is the basis for the veracity of an account, empirical evidence cannot be the basis for moral and religious views. Abortion is right or wrong cannot be reduced to an empirical given.

Depending on whether beliefs are ambiguous or not, beliefs are considered as being either de dicto or de re. If the pronoun is ambiguous (John knows that he is tall) or the noun is not replaceable, then it is considered as de dicto. On the other hand and if the pronoun is clear and the noun is replaceable (Superman is Kent Clark) then it is considered as de re. Here again, if the ambiguity is de dicto, then it involves empirical justification; on the other hand, if the ambiguity is $d e r e$, then extra-empirical or phenomenological conjecture is required.

Depending on whether beliefs are sense-assertive or self-assertive truths, the established truth is either empirically true or metaphysically true. Sense assertive truths can be an empirical given. However, self-assertive truths cannot be an empirical given. As such, while sense assertive truth can be verified, self-assertive 
truths cannot be verified. Someone's like or dislikes cannot be empirically verified. As such, existential and metaphysical assertions such as "I like chocolate, "'I am free," or "I believe in God "do not require anything more or less than their claim. Existential or metaphysical beliefs can be held with or without, against, or regardless of empirical evidence because phenomenological justification or conjectures is the only basis for holding such beliefs. Humans do not choose to be conscious, have a conscience, or be free; humans are conscious, have a conscience, and are free. To be conscious, have a conscience and be free is an existential given. Empirical justification cannot establish nor negate these metaphysical claims. When we accept the cognitive self, the volitional self, the moral self, and the divine self, metaphysics is a given. We are born to be metaphysicians either in the acceptance or the rejection of metaphysical truths. That is why while we have the freedom to accept or reject metaphysical truths, we do not have the freedom to escape from metaphysical truths. As such, metaphysical beliefs are belief decisions for or against what his known, as such in the words of Kierkegaard, an either/or matter (Kierkegaard 1987, p. 176).

Depending on whether beliefs are considered as a paradigm or a principle ${ }^{10}$, beliefs can be either a factual given or a phenomenological given. While what is considered as a factual given can have an empirical basis, what is considered as a phenomenological given does not need an empirical basis. For instance, belief in the cosmic inflation theory or the creation and expansion of the present universe by repulsive gravity is a demonstrable hypothesis ${ }^{11}$. However, belief in the self as a phenomenological given is not an empirically demonstrable given. Though MRI imaging can detect whether one's brain is dead or alive, it cannot tell whose brain is alive or dead. The conscious self is undetectable. The assertion that the creation and the expansion of the universe happened in less than a second, resulting in a flat universe, ${ }^{12}$ is again demonstrable. However, there is no empirical evidence as to how and when insentient matter becomes sentient. Empirical evidence is one way but not the only way we can demonstrate truth. What is reductive (water is $\mathrm{H} 2 \mathrm{O}$ ) is a factual or an empirical given. Dissimilarly, what is non-reductive (the self and freedom) is a phenomenological given without an empirical basis. Only phenomenology can allow us to understand the reality of the self and freedom.

\footnotetext{
${ }^{10}$ Axiomatic.

${ }^{11}$ Alan Guth explains inflation theory. Available at: https://www.youtube.com/watch?v=rEXD gpttmyc.

${ }^{12}$ Alan Guth explains inflation theory. Available at: https://www.youtube.com/watch? $v=r E X D$ gpttmyc. (It appears flat because the north/south circumference is smaller than the east/west circumference\}. It appears that the empirical evidence that the creation and expansion of the universe was accomplished faster than the speed of light.is the basis for the reality of the universe.
} 


\section{Conclusion}

Beliefs can be held with or without, against, or regardless of empirical evidence because empirical evidence is one way but not the only way of knowing reality. Beliefs as mental states can be defined either as being a priori or a posteriori; basic or non-basic, contingent or necessary, volitional or non-volitional, verifiable or not verifiable, falsifiable or unfalsifiable, de dicto or de re, closed or open. Depending on whether beliefs are sense-evident or self-evident, beliefs are either synthetic or analytic. Depending on whether beliefs are supported by other beliefs or not, beliefs are either basic or non-basic. Depending on whether beliefs are true in a given world or true in all possible worlds, beliefs are either contingent or necessary. Depending on whether what we know is caused or chosen, beliefs are either volitional or non-volitional. Depending on how beliefs are ascertained, beliefs are either confirmable or falsifiable. Depending on whether beliefs we hold are mind-dependent or mind-independent, beliefs are justified empirically or nonempirically. Depending on the ambiguity of a sentence, beliefs are either de dicto or $d e$ re. Depending on whether beliefs are considered as a paradigm or model, beliefs can be either empirically demonstrated or phenomenally acknowledged. Depending on whether beliefs are defined as true or false, beliefs are considered either 'closed' or 'open.' Depending on whether beliefs are understood as a paradigm or a principle, beliefs can be either a factual given or a phenomenological given. Acceptance of reductive or empirical beliefs is mandatory as such non-volitional. Acceptance of beliefs that are non-reductive or metaphysical is not mandatory as such volitional. We are born to either accept or reject metaphysical truths. Whether you affirm or deny metaphysical truths, we are all metaphysicians. Existential assertions and phenomenological conjectures can be accepted with or without, against, or regardless of empirical evidence.

Beliefs as mental states are about what is physical or about what is phenomenological. Beliefs related to the physical are reductive; beliefs related to what is phenomenological are non-reductive. Both empirical and extra-empirical justification play an important role in belief-formation in science and metaphysics alike. While 'reality' is either mind-independent or mind-dependent, beliefs about reality are either empirically justified or extra-empirically justified. Beliefs related to mind-independent realities like that of matter or what is physical are inductive and reductive. Beliefs related to mind-dependent realities are either like mathematics, deductive, non-reductive, non-physical, non-spatial, and non-temporal, having an abstract location, or like morals, non-reductive, intentional, and irrefutable, having an abstract location in one's mind. As such, beliefs about reality are either verifiable, falsifiable or unfalsifiable. Verifiable and falsifiable beliefs (related to the physical or material world), are inductive and reductive and can be verified or falsified by empirical methods. However, unfalsifiable or irrefutable beliefs (related to the psychical or mental world), which are deductive and non-reductive, cannot be ascertained by empirical justification. Evidence or justification for beliefs are not limited to empirical evidence alone; it can involve extra-empirical justification. As such, questions, postulates and paradigms, and phenomenological conjectures provide justification for non-empirical beliefs. There can be no need 
for empirical justification for non-reductive existential assertions or phenomenological conjectures--such as belief in the self, freedom, and belief in God. The phenomenal self and freedom are non-reductive realities similar to what is at the quantum level. Empirical justification cannot establish nor negate existential assertions and phenomenological conjectures. When we recognize the nature of different types of beliefs: we (1) understand why we can accept beliefs with or without; against or regardless of empirical evidence, (2) understand when the acceptance of beliefs is mandatory or non-volitional and when the acceptance of beliefs is non-mandatory or volitional. (3) Understand when to define beliefs as justified true belief and when to define beliefs as justified belief-decision. For all phenomenological beliefs are accompanied by a decision for or against what is comprehended.

\section{References}

Ajayi V (2017) Science knowledge is testable, falsifiable and verifiable $\mathrm{DOI}=10.13140 /$ RG.2.2.24109.18407.

Alston W (1993) Has foundationalism been refuted. In MF Goodman, RA Snyder (eds.), Contemporary Readings in Epistemology. NJ: Prentice Hal.

Ayer AJ (1946) Language, truth and logic. New York: Dover.

Brentano F (2002) The distinction between mental and physical phenomena. In DJ Chalmers (ed.), Philosophy of Mind. New York: Oxford University Press.

Block N (2002) Concepts of Consciousness. In DJ Chalmers (ed.), Philosophy of Mind. New York: Oxford University Press, 2002.

Carnap R (1946) Remarks on induction and truth. Philosophy and Phenomenological Research 6(Jun): 997.

Chalmers D (2016) Are there things not material. Available at: https://www.youtube.com/ watch?v =f0QPWQR5f9Q.

Chisholm RM (2002) Intentional inexistence. In DJ Chalmers (ed.), Philosophy of Mind. New York: Oxford University Press.

Conee E (1988) The basic nature of epistemic justification. The Monist 71(3): 389-404.

Engel P (2004) Truth and the aim of belief. Laws and Models in Science (Jan): 77-97.

Gettier EL (1993) Is justified true belief knowledge? In MF Goodman, RA Snyder (eds.), Contemporary Reading. NJ: Prentice Hall.

Gezelter JD (n.d.) Open science and verifiability. Available at: https://openscience.org/wpcontent/uploads/2009/11/PositionPaper1.pdf.

Goodman MF, Snyder RA (1993) Contemporary readings in epistemology. Englewood Cliffs NJ: Prentice Hall.

Grattan-Guinness (2004) "The problem of induction": a fresh look at the logic of scientific theories. Ekenntnis 60(1): 107-120.

Greene B (2019) What is string theory. Available at: https://www.youtube.com/watch?v =TI6sY0kCPpk\&ab_channel=WorldScienceFestival.

Hempel CG (1935) On the logical positivists' theory of truth. Analysis 2(4): 49-59.

Herrick P (1994) The many world of logic. Fort Worth: Harcourt Bruce College Press.

Hume D (2004) An inquiry concerning human understanding. In S Luper (ed.), Essential Knowledge. New York: Pearson Longman.

Kant I (1991) Prolegomena to any future metaphysis. In RC Hoy, LN Oaklander (eds.), Metaphysics. Belmont: Wadsworth Publishing company. 
Kierkegaard S (1987) Either/Or. Edited by HV Hong, EH Hong. Volume 2. New Jersey: Princeton UP.

Kripke S (1980) Naming and necessity. Cambridge: Harvard University Press.

Maudlin T (2020) What exists. Available at: https://www.youtube.com/watch?v=anydSV dXbck.

McNaughton SJ (1999) What is good science? Natural Resources \& Environment 13(4): 513-518.

Northcott R (2019) Free will is not a testable hypothesis. Erkenntnis 84(3): 617-631.

Olszewski W, Sandroni A (2011) Falsifiability. The American Economic Review 101(2): 788-818.

Plato. Theaetetus.

Plato. Meno.

Pojman LP (1985) Believing and willing. Canadian Journal of Philosophy 15(1): 37-55.

Popper K (2016) Science, and pseudoscience: crash course philosophy \#8. Available at: $\mathrm{https}: / / \mathrm{www}$. youtube.com/watch?v=-X8Xf10JdTQ.

Rosenthal D (2002) Explaining consciousness. In D Chalmers (ed.), Philosophy of Mind. New York: Oxford University Press.

Samraj T (2007) What is your belief quotient? Bloomington, IN: Authorhouse.

Sher G (2001) Moral philosophy Belmont: Wadsworth.

Swinburne R (2004) The existence of God. Oxford: Clarendon Press.

Swinburne R (n.d.) Is God necessary. Available at: https://www.closertotruth.com/intervi ews/4311.

Tarski A (1993) The semantic conception of truth. In MF Goodman, RA Snyder (eds.), Contemporary Reading. NJ: Prentice Hall.

Walls A (2014) Reasonable unfalsifiable beliefs. Available at: http://www.wall.org/ aron/ blog/reasonable-unfalsifiable-beliefs/.

Wigmore I (2017) What is falsifiability. Available at: https://whatis.techtarget.com/definiti on/falsifiability.

Wilkinson S (2016) Can there be belief without evidence? Teorema: Revista Internacional De Filosofía 35(1): 13-34.

Williams M (2001) Problems of knowledge. Oxford: Oxford Press. 